Ärztliche Erfahrung beschränkt sich nicht auf medizinisches Fachwissen.

\section{Wenigstens sind die Eier heil}

_ Neulich kam ein junger Student zu mir in die Praxis. Er war im Supermarkt über einen Verpackungsdraht gestolpert und dann mit seinem ganzen Gewicht auf das rechte Knie gefallen. Nun hatte er Schmerzen und zeigte mir den großen Bluterguss, den er von dem Sturz davongetragen hatte. Ich untersuchte ihn gründlich und versorgte ihn mit einem Salbenverband. Da zog er plötzlich eine hellgrüne, rechteckige Pappschachtel aus seiner Supermarkttüte und kommentierte begeistert: „Aber die Eier sind heil geblieben, Frau Doktor!“ Ich verkniff mir ein Lachen und nahm mir vor, diese lustige Geschichte im Laufe des Tages aufzuschreiben.
Noch viel komischer als die Geschichte an sich war dann aber die Reaktion meiner Mitarbeiterinnen auf meinen darauf folgenden Eintrag im PC: Um die kleine Anekdote nach der Sprechstunde niederzuschreiben, gab ich den Patienten noch einmal in die Wartezimmerliste ein und fügte als Kommentar hinzu: „Aber die Eier sind heil geblieben.“ Meinen Mitarbeiterinnen war beim Durchgehen der Liste der vermeintlich frivole Text natürlich aufgefallen. Daraufhin zog mich jede einzelne von ihnen eifrig mit der Frage nach Aufklärung des Sachverhaltes beiseite. Honi soit qui mal y pense!

Dr. Luise Hess, Darmstadt

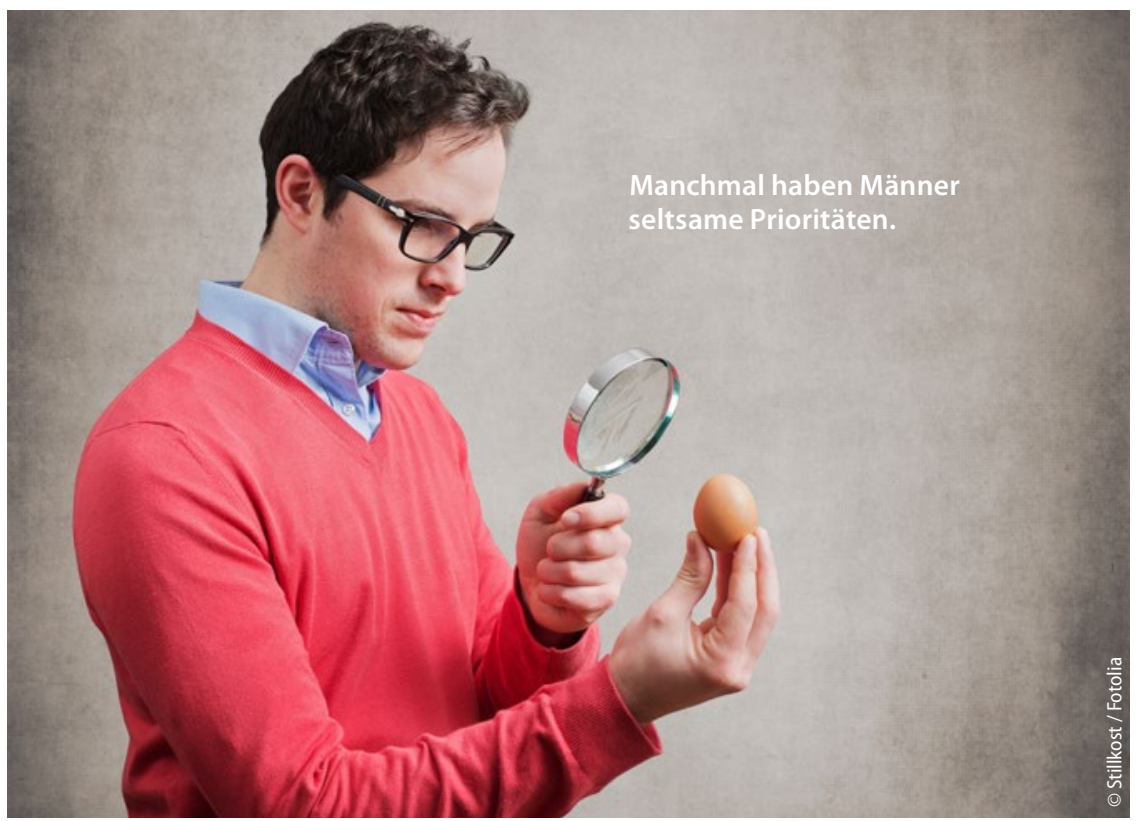

Termin beim etwas anderen Urologen

Meine kleine, stets freundliche $\mathrm{Pa}$ tientin aus Ostpreußen hört sehr schlecht. Ihr Hörgerät möchte sie dennoch nicht tragen. Trotzdem konnten wir uns bisher durch lautere Unterhaltungen immer gut verständigen - bis sie mich eines Tages um eine „Überweisung zum Urologen“ bat. „Zum Urologen? Was wollen Sie denn da? Haben Sie Probleme mit Ihrer Blase?", fragte ich sie. Sie lachte: „Nein, habe ich nicht. Ich möchte auch gar nicht zu dem Urologen, sondern zu dem anderen." Jetzt war ich ratlos. Welchem anderen? „Ja, wie heißt der noch mal?", überlegte sie. „Ich hab's!“, rief sie laut. „Ich möchte nicht zum Urologen, sondern zum Ne-Urologen!"

Nun mögen Urologen zwar über einige Subspezifikationen verfügen, von einem "Ne-Urologen“ hatte ich bis dato aber noch nie etwas gehört. „Ne-Urologe!" wiederholte sie, noch lauter als zuvor, und dann fiel bei mir endlich der Groschen, bzw. der Cent: „Sie möchten wegen Ihres Schwindels zum Neurologen, stimmt's?“ Da strahlte sie: „Ja, genau das möchte ich! Ich sagte doch: $\mathrm{Zu}$ dem anderen Urologen, dem Ne-Urologen eben".

Nun waren wir handelseinig, und strahlten beide: sie wegen der Überweisung, und ich wegen der schönen Geschichte.

Dr. Frauke Höllering, Arnsberg 